\title{
Dynamic Atomic Force Microscopy of RecA/DNA System
}

\author{
Bernie D. Sattin*, and M. Cynthia Goh
}

*Department of Chemistry, University of Toronto, 80 St. George St., Toronto, ON, Canada, M5S 3H6.

Using the Atomic Force Microscope (AFM), we have begun to study the bacterial recA system. This system is largely responsible for most of bacterial genetic diversity. The proteins recA, and recBCD play dominant roles in several key functions, including SOS DNA repair and homologous recombination. This system also has implications for eukaryotes, and arachaea, as Rad51 protein has been shown to perform the same function in higher mammals, as does prec in the archaea.

The AFM is just over 15 years old, and is still finding its experimental niche. The AFM possesses many qualities of interest to those examining biological phenomena. It offers resolution comparable to or better than standard electron microscopes (EM), while allowing a user to perform their experiments under any conditions. This is due to the fact that the AFM operates on the principle of visualization by feeling a surface in lieu of visualization by bombardment of an object with electrons. The benefit of being able to use a wide range of conditions is the ability to image biological specimens in their natural state (i.e. at physiological conditions), and, more importantly, in a state where they still retain some, if not all, of their biological function.

The goal of our experiment is to visualize the binding of recA protein to DNA, and follow the events of homologous recombination, and SOS DNA repair. To achieve this goal, one must be able to visualize recA protein, DNA, and recA/DNA complexes both alone and together, then search for conditions that allow the recA and DNA to move on the surface. These states are shown in Figure 1. The images shown in Figure 1 are acquired under buffer, and neutral pH, or in air. In order to get an idea of the time scales involved in the formation of the recA/DNA complex, we performed a time resolved AFM study in air. In addition, we are driving towards performing all of our experiments at physiological temperature. We have recently constructed a well performing temperature control fluid cell for our AFM. Its performance can be seen in Figure 2. This is an image of $\phi X 174$ plasmid DNA was acquired under true physiological conditions $-100 \mathrm{mM}$ salt, $\mathrm{pH} 7.4,37^{\circ} \mathrm{C}$.

Here we present the time-resolved study of the formation of the RecA/DNA complex, as well as the successful transition to imaging under true physiological conditions. Finally, we discuss our preliminary studies of dynamically imaging recA complexes under physiological conditions [1].

\section{References}

[1] This research was funded by a grant from the Natural Sciences and Engineering Council of Canada. 

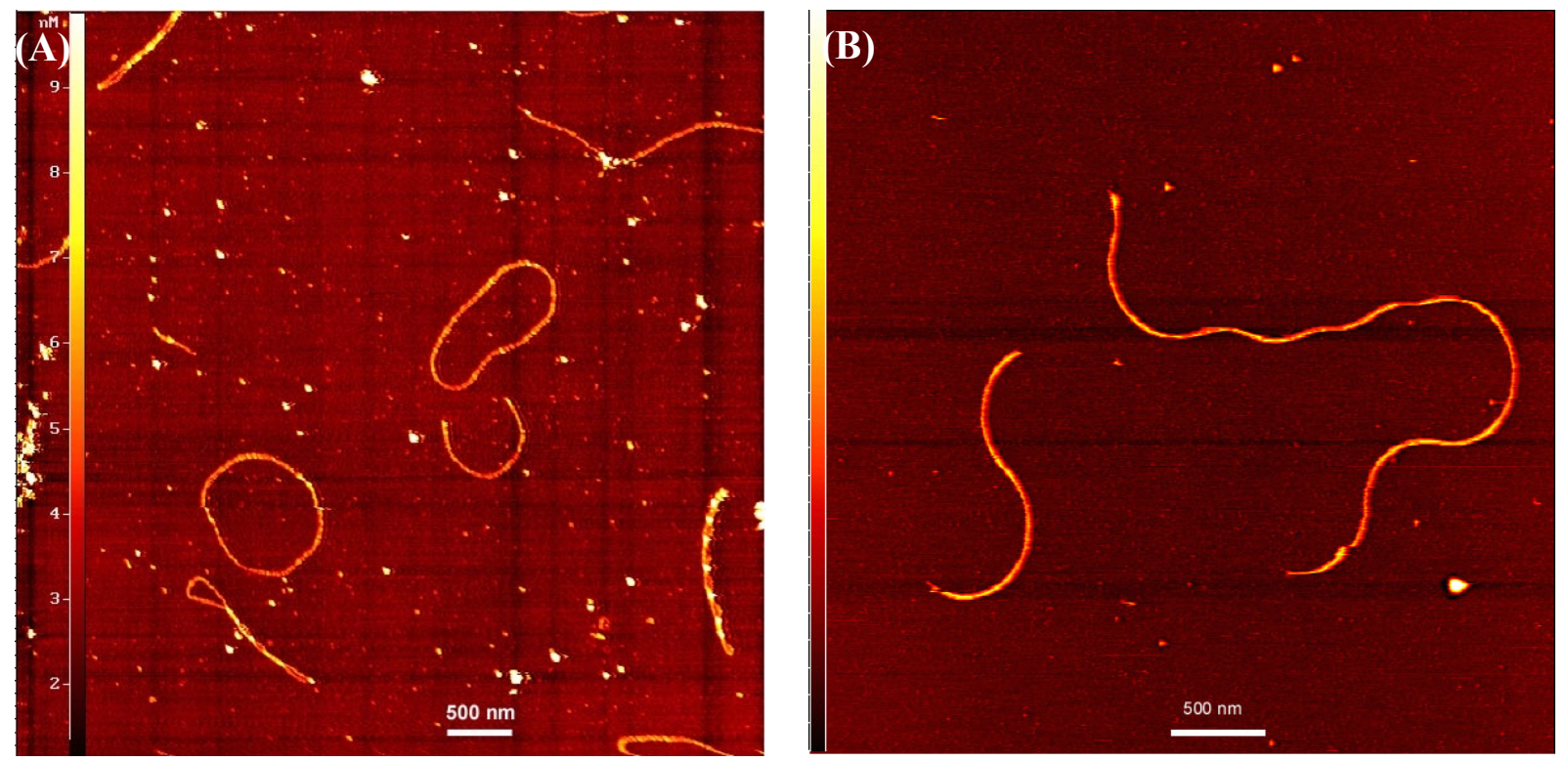

Figure 1. (A) RecA/DNA complex formed in solution and imaged in air. Z scale represents $10 \mathrm{~nm}$. (B) RecA only complex formed in solution, imaged in solution. $Z$ scale represents $15 \mathrm{~nm}$.

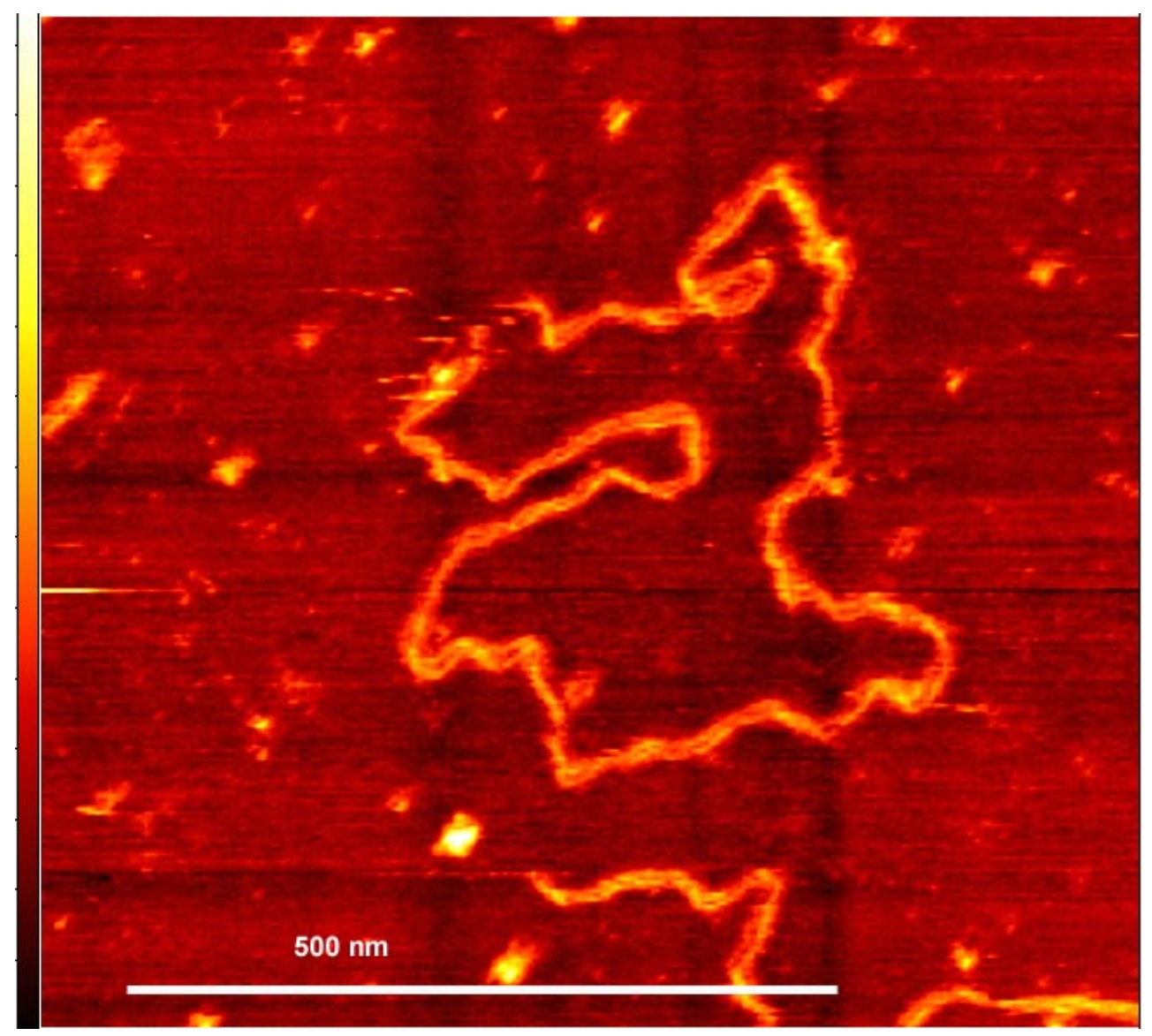

Figure 2. $\phi X 174$ double stranded plasmid DNA imaged in solution, at physiological temperature, salt and $\mathrm{pH}$. Z-scale is $5 \mathrm{~nm}$. 